\title{
有机物/硅杂化太阳能电池的研究进展
}

\author{
刘瑞远 孙宝全* \\ (苏州大学功能纳米与软物质研究院 苏州 215123)
}

\begin{abstract}
摘要 有机/无机杂化太阳能电池既可以兼容无机材料的高稳定性, 高载流子迁移率和成熟的制备工艺, 又可以利用 有机材料分子结构的可塑性, 调节光谱吸收以及光学带隙, 以及简便的溶液制作过程, 具有取得高效率低成本太阳能 电池的巨大潜力. 硅和有机物在低温下形成的异质结光伏电池吸引了广泛的研究, 目前最高光电转换效率已经达到 13.8\%. 而采用硅纳米线等纳米结构之后使在几十微米的低纯硅上制备高效太阳能电池成为可能, 柔性硅基底的杂化 太阳能电池效率已经超过 $12 \%$. 本文首先介绍了硅基杂化太阳能电池的结构、工作机理和使用的有机材料, 按硅的结 构分为平面硅基和微纳结构硅基杂化太阳能电池, 重点概述了该类电池最近几年的发展状况, 分析了硅的结构、有机 材料和制备工艺对器件性能的影响. 最后对众多研究方法进行了归纳总结, 对存在的问题和解决策略提出了展望.
\end{abstract}

关键词 硅结构; 有机物; 溶液旋涂; 界面优化; 杂化太阳能电池

\section{Silicon-based Organic/inorganic Hybrid Solar Cells}

\author{
Liu, Ruiyuan Sun, Baoquan* \\ (Institute of Functional Nano \& Soft Materials (FUNSOM), Soochow University, Suzhou 215123)
}

\begin{abstract}
Organic-inorganic hybrid solar cells display potential to be high efficiency and low cost photovoltaics due to combined advantages of high stability, high mobility and well developed fabrication process from inorganic materials and the properties to adjust organic molecule structure, absorption spectrum and bandgap from solution processable organics. Heterojunction photovoltaics formed by silicon and organics at low temperature has drawn great interests over past five years and the reported highest power conversion efficiency (PCE) has achieved up to $13.8 \%$. The emerging of nanotechnology allows for silicon micro/nano structures including silicon nanowires, pyramids and nanocones with excellent light absorption properties which can greatly reduce the consumption of silicon materials as well as the purity dependence. The micro/nano structures also exhibit the advantages to offer larger junction area and more effective separation pathways for charge carriers. It is noticeable that silicon nanowire-based flexible hybrid solar cells with tens of micrometers silicon substrate thickness have achieved the PCE of above $12 \%$ adopting the most popular commercialized conjugated polymer poly(3,4-ethylenedioxythiophene): poly(styrenesulfonate) (PEDOT:PSS). With the rapid developments of new organic materials and interface engineering methods, different kinds of organic-silicon hybrid solar cells has been reported and shown superior photovoltaic characteristics. The adopted organics include PEDOT:PSS, poly(3-hexylthiophene) (P3HT), 2,2',7,7'-Tetrakis-(N,N-di-4-methoxyphenylamino)-9,9'-spirobifluorene (Spiro-OMeTAD), poly(3-octylthiophene) (P3OT), fullerene derivative and so on. This paper reviews the device structures of silicon-based hybrid solar cells, working mechanism and related organic molecular. The hybrid heterojunction with different materials and fabrication processes has been discussed. The last section summarizes the method used to improve the performance of the hybrid solar cells and depicts the challenges and prospects of the silicon-based hybrid solar cells in the near future.
\end{abstract}

Keywords silicon structures; organics; solution spin-coating process; optimization of interface; hybrid heterojunction solar cells

\section{1 引言}

随着能源危机的加剧和环境问题的日趋严重, 太阳 能已经引起了各国政府的广泛关注. 从 1954 年美国贝 尔实验室研制出第一个硅太阳能电池以来, 经过数十年 的研究发展, 单晶硅和多晶硅太阳能电池的转换效率已 经达到了 18\% 25\%, 这类电池又被称为第一代太阳能
电池. 第二代太阳能电池是基于 II-VI族半导体，铜铟镓 硒和无定形硅的薄膜太阳能电池, 最高的转换效率已经 接近 $20 \%{ }^{[1]}$. 硅基太阳能电池且因其成熟的工艺, 高的 转换效率, 组件良好的稳定性和无毒害的丰富来源占据 了 $80 \%$ 以上的太阳能市场份额. 而第三代太阳能电池则 致力于发展高效率低成本太阳能电池, 如叠层太阳能电

* E-mail: bqsun@suda.edu.cn; Tel.: 0086-0512-65880951

Received October 9, 2014; published February 2, 2015.

Project supported by the National Basic Research Program of China (973 Program) (No. 2012CB932402), the National Natural Science Foundation of China (Nos. 61176057, 91123005, 60976050), and the Priority Academic Program Development of Jiangsu Higher Education Institutions.

项目受国家 973 基础研究项目(No. 2012CB932402)、国家自然科学基金(Nos. 61176057, 91123005, 60976050)和江苏高校优势学科建设工程资助项目 资助. 
池, 有机太阳能电池和有机一无机杂化太阳能电池等. 占据市场主导的单晶硅和多晶硅太阳能电池虽然目前 效率非常可观, 但是对硅片纯度的高要求和复杂的制备 流程使其成本居高不下，限制了其更大范围的应用.

1986 年, $\mathrm{Tang}^{[2]}$ 报道了第一个有机太阳能电池, 虽 然效率只有 $0.95 \%$, 但是开创了利用有机半导体材料将 太阳能转化为电能的先河. 有机太阳能电池是以碳碳单 键和碳碳双键作为支架的碳基有机半导体为主体, 电子 沿着共轭支架传输, 通常采用 $\mathrm{p}$-型给体. 因其较低的制 备成本, 简单的工艺和不断提升的转换效率以及可以在 柔性基底上实现大面积应用, 有机太阳能电池已经成为 了新一代太阳能电池的重要力量, 在过去的数十年备受 瞩目, 目前单结最高转换效率已经超过 $10 \%^{[3]}$. 但是由 于聚合物和小分子的纯有机太阳能电池也存在其固有 的缺点, $\mathrm{n}$-型有机半导体的电子迁移率相对于 $\mathrm{p}$-型半导 体的空穴迁移率而言比较低, 成为了有机太阳能电池应 用的主要障碍. 在活性层电子和空穴传输的不平衡导致 光生载流子会在给体-受体界面产生一个阻碍电荷有效 传输并产生复合的区域. 有机半导体的激子扩散长度通 常只有 5 20 nm, 而单晶硅的少子扩散距离在数十到 数百微米, 因此不仅载流子的分离受到极大影响, 活性 层的最大厚度也受到了限制. 除此之外, 有机太阳能电 池的稳定性也成为制约其发展的重要因素 ${ }^{[4]}$.

典型的单晶无机半导体因为其良好的晶型, 迁移率 大约在 $10^{3} \mathrm{~cm}^{2} /(\mathrm{V} \cdot \mathrm{s})$ 量级 $(\mathrm{n}-\mathrm{Si}$ 载流子迁移率大约为 $\left.1350 \mathrm{~cm}^{2} /(\mathrm{V} \bullet \mathrm{s})\right)$, 而有机半导体则只有 $10^{-3} \sim 10$ $\mathrm{cm}^{2} /(\mathrm{V} \cdot \mathrm{s})$. 同时无机半导体制备的器件稳定性也很高, 许多商业硅太阳能电池组件的寿命可达 20 年以上. 导 致硅太阳能电池成本居高不下的主要原因之一是复杂 的硅提纯和器件的制备工艺, 分别构成了约 50\%和约 $25 \%$ 的组件成本 ${ }^{[5]}$. 传统的硅太阳能电池为了实现高效 的电荷分离, 需要在电池表面形成 $\mathrm{p}-\mathrm{n}$ 结, 而结的形成 通常是通过离子注入和退火或者热扩散过程实现, 每个 步骤都需要大约 $1000{ }^{\circ} \mathrm{C}$ 的高温. 有机-无机杂化太阳 能电池可以结合这两类不同材料的特性, 既可以利用无 机材料的高稳定性, 高载流子迁移率和成熟的制备工 艺, 同时也可以兼容有机材料分子结构的可塑性, 调节 光谱吸收以及光学带隙, 以及简便的溶液制作过程. 另 外, 通过常温或者低温过程形成的有机一无机异质结既 能简化流程, 降低成本, 同时又避免了高温过程对结区 的不利影响，期望可以获得可观的光电转换效率.

1990 年加州理工学院的 Lewis 课题组在 $\mathrm{n}$ 型硅片 (n-Si)上旋涂了透明的聚硅甲基-环四辛基 (poly$\left(\mathrm{CH}_{3}\right)_{3} \mathrm{Si}$-cyclooctatetraene), 并且用碘液掺杂形成了表 面势垒太阳能电池, 产生了比 $\mathrm{n}-\mathrm{Si}$ / 金属肖特基器件更 高的电压 ${ }^{[6]}$. 自从 2002 年加利福尼亚州立大学伯克利分 校的 Alivisatos 课题组里程碑式地报道了将硒化镉 (CdSe)纳米棒和共轭聚合物聚 3-已基噻吩(P3HT)共混
制备杂化太阳能电池并获得了 $1.7 \%$ 的能量转换效率之 后, 有机一无机杂化太阳能电池开始引发了广泛的关注, 该文献至今引用已经超过 4400 次 $^{[7]}$.

\section{2 硅基有机/无机太阳能电池}

硅作为地球上储量第二大的元素, 以其为基底的杂 化太阳能电池吸引了广泛的关注. 在合适的能带条件 下, 聚(3,4-亚乙二氧基噻吩)-聚(苯乙烯磺酸)(poly(3,4ethylenedioxythiophene):poly(stylenesulfonate), PEDOT: PSS), 聚 3-已基噻吩(poly(3-hexylthiophene), P3HT), 聚 3 - 辛基噻吩(poly $(3$-octylthiophene), P3OT), 聚 (2-methhoxy-5-(2-ethylhexyloxy)-1,4-pheneylenevinylene) (PEH-PPV), 小分子 2,2',7,7'-Tetrakis-( $N, N$-di-4-methoxyphenylamino)-9,9'-spirobifluorene (Spiro-OMeTAD)等 $\mathrm{p}$-型有机物可以与 $\mathrm{n}-\mathrm{Si}$ 形成异质结并传输空穴, 或者富 勒烯衍生物 $(\mathrm{PCBM})$ 等 $\mathrm{n}$ - 型有机物与 $\mathrm{p}-\mathrm{Si}$ 接触并传输电 子, 这些有机物的分子结构如图 2 所示. 除了有机物以 外, 硅还可以和其他的碳材料如碳纳米管和石墨烯等形 成异质结.

与传统的硅 $\mathrm{p}-\mathrm{n}$ 结太阳能电池相似, 硅基有机-无 机杂化太阳能电池工作过程也分为几个步骤：光的吸 收、光生载流子(电荷)的产生和扩散、光生载流子在结 区的分离和电极的收集. 以最简单的 $n$-型平面硅-有机 物杂化太阳能电池为例, 首先能量高于半导体带隙的光 子被吸收(即光由硅吸收), 产生电子和空穴对. 有机物 和硅形成一个结区, 产生在结附件扩散长度范围的光生 载流子扩散到空间电荷区，在电场的作用下分离. 电子 在 $n$-型半导体(此处为 $n-S i$ )中传输到阴极中, 空穴在 $p$ 型半导体中传输到阳极中(如图 1 所示). 阴极材料通常 采用热蒸镀或者溅射低功函的铝，钙或者镁，用来收集 电子; 阳极材料采用高功函的金或者银等金属, 用来传 输空穴. 硅在光照下产生光生载流子, 有机物形成结区 和传导电荷, 所以载流子在界面处的分离和传输效率相 比有机太阳能电池要大大提高. 关于电池的稳定性, 有 研究表明, 在适当的界面处理下，未经过封装的硅杂化 电池在大气环境中放置几个月后性能仍没有明显的衰 减, 优于有机太阳能电池 ${ }^{[8]}$.

用平面硅和有机物制备的杂化太阳能电池虽然制 备简单，但是平面硅较高的反射率 $(\sim 35 \%)$ 使得电池的 电流远远低于单晶硅太阳能电池, 纳米技术的迅速发 展, 为杂化太阳能电池带来了新的效率提升空间. 硅纳 米线 ${ }^{[9 \sim 13]}$, 硅纳米孔 ${ }^{[14 \sim 16]}$ 以及金字塔 ${ }^{[17 \sim 19]}$ 结构具有很 强的陷光能力，几十微米的基底就可以吸收相当于平面 硅几百微米厚度的光, 可以大大减少使用的硅材料, 对 于降低器件成本有着重要的作用; 比表面积的增大，又 使得结区的面积也大大增加, 提高了载流子的分离效 率. 本文按有机-无机杂化太阳能电池中硅的结构分为 平面硅和硅微纳结构两部分, 介绍硅基杂化太阳能电池 

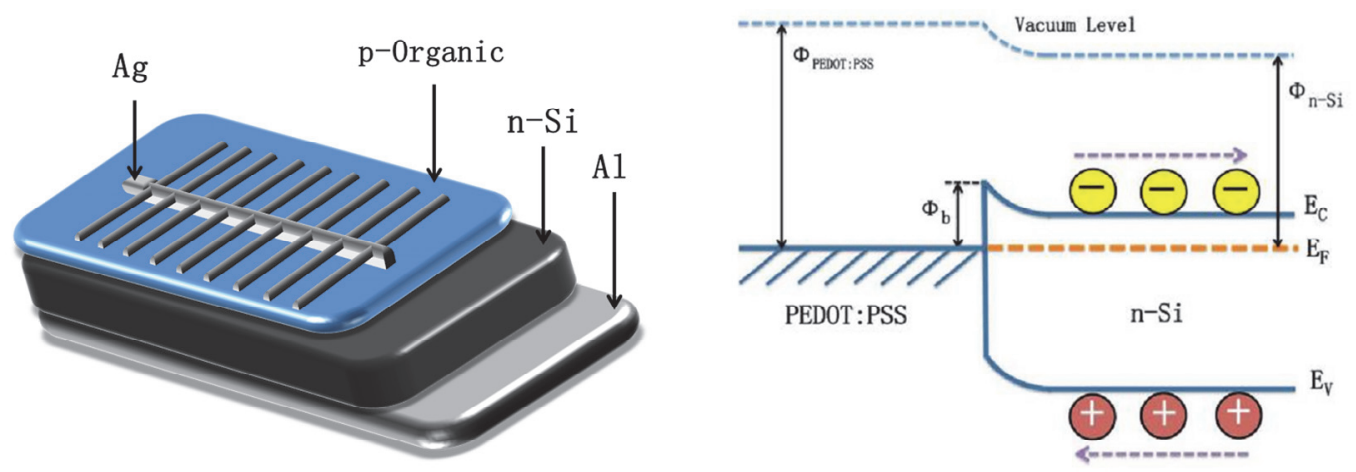

图 1 硅基杂化太阳能电池的基本结构(左图)和能带结构示意图(右图)

Figure 1 Basic structure of a silicon based hybrid solar cell (left) and scheme of the operating principles (right)

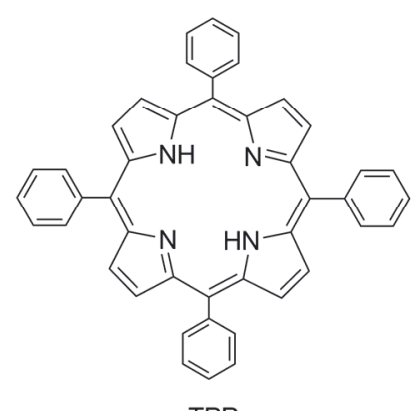

TPP



MEH-PPV

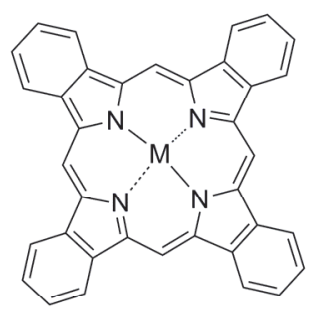

$\mathrm{M}=\mathrm{Mg}, \mathrm{MgPc}$

$\mathrm{M}=\mathrm{Ni}, \mathrm{NiPc}$

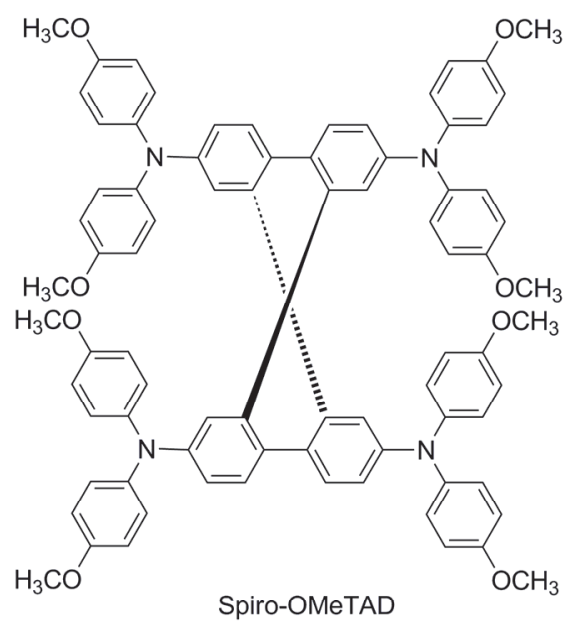<smiles>CCCCCc1cc(C(C)(C)C)sc1C(F)(F)F</smiles>

P3OT<smiles>CC(C)(C)c1cc(CBr)c(CBr)s1</smiles>

P3HT<smiles>CC(C)(C)c1sc(C(C)(C)C)c2c1OCCO2</smiles><smiles>CCC(C)C(C)CC</smiles>

PEDOT:PSS

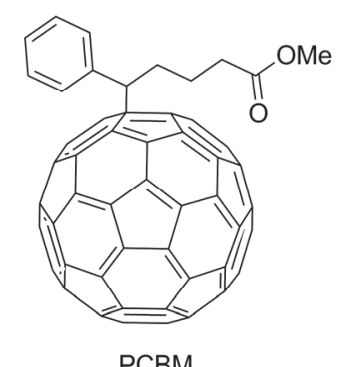

Spiro-OMeTAD

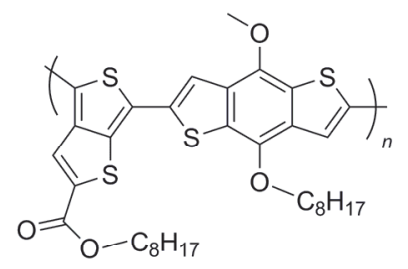

PTB7

图 2 有机-硅杂化太阳能电池中使用的有机物及其分子结构

Figure 2 The molecule structures of the organics used in organic-silicon hybrid solar cell

的研究进展.

\section{3 基于平面硅的有机/无机杂化太阳能电池}

早在晶硅太阳能电池迅猛发展的 1990 年代, 加州 理工学院的 Lewis 课题组就制备了聚硅甲基-环四辛基/ $\mathrm{n}$-硅(poly- $\left(\mathrm{CH}_{3}\right)_{3} \mathrm{Si}$-cyclooctatetraene/n-Si) 杂化太阳能电 池, 用碘液掺杂聚合物之后制备的电池显示出了比传统 金属 $/ \mathrm{n}$-硅太阳能电池更高的开路电压(如图 3 所示) ${ }^{[6]}$. 金属和硅接触的界面由于在硅/金属处的化学反应, 生 成金属硅化物, 发生钉扎现象. 在硅和金属的界面具有 极高电荷复合速率, 导致了它们较差的光伏性能, 使得 电池的开路电压和转换效率都比较低. 而碘掺杂的聚合
物可以通过传统的肖特基势垒产生更高的开路电压，并 且测得的电压是表面势垒器件中能够获得的最大值. 基 于有机物和硅的电池体复合速率非常低, 表明在硅/有 机物界面处的载流子损失几乎可以忽略, 未经过优化的 器件产生了 $1 \% \sim 5 \%$ 的光电转化效率.

十几年之后, 有机/无机太阳能电池开始因其低廉 的成本和简易的工艺吸引了广泛的关注, 并成为新一代 的太阳能电池之一. 人们将不同的有机物(PEDOT:PSS, P3HT, P3OT, Spiro-OMeTAD, PCBM 等)应用到硅基器 件中, 并且对有机物的性能以及硅/有机物界面进行了 大量研究, 同时器件工艺也在不断改进(结构, 电极), 取得了长足的发展(详见表 1 和表 2). 
表 1 基于平面硅的杂化太阳能电池光伏性能

Table 1 Photovoltaic properties of planar silicon-based hybrid solar cell

\begin{tabular}{|c|c|c|c|c|c|c|c|}
\hline Device Structure & Area $/ \mathrm{mm}^{2}$ & $J_{\mathrm{sc}} /\left(\mathrm{mA} \cdot \mathrm{cm}^{-2}\right)$ & $V_{\mathrm{oc}} / \mathrm{V}$ & $\mathrm{FF}$ & $\mathrm{PCE} / \%$ & Year & Ref. \\
\hline $\mathrm{Au} / \mathrm{p}-\mathrm{MgPc} / \mathrm{n}-\mathrm{Si} / \mathrm{In}$ & 95 & 3.76 & 0.35 & 0.40 & 1.05 & 2000 & 20 \\
\hline $\mathrm{Au} / \mathrm{NiPc} / \mathrm{p}-\mathrm{Si} / \mathrm{Al}$ & 25 & 12.39 & 0.32 & 0.28 & 1.11 & 2005 & 22 \\
\hline $\mathrm{Au} / \mathrm{TPP} / \mathrm{n}-\mathrm{Si} / \mathrm{Al}$ & 25 & 2.76 & 0.25 & 0.37 & 2.45 & 2005 & 23 \\
\hline Pd/n-Si/i-Si/i-Si:H(a)/PEDOT:PSS/ITO/Glass & - & 4.55 & 0.883 & 0.51 & 2.1 & 2005 & 21 \\
\hline $\mathrm{Au} / \mathrm{PANI} / \mathrm{n}-\mathrm{Si} / \mathrm{Al}$ & - & 17 & 0.51 & 0.41 & 3.55 & 2007 & 30 \\
\hline Pd/Ag/EPDOT:PSS/P3HT/n-Si/Al & 3.1 & 29 & 0.59 & 0.59 & 10.1 & 2011 & 24 \\
\hline Ag/PEDOT:PSS-Zonyl/n-Si/Al & 25 & 29.20 & 0.541 & 0.718 & 11.34 & 2012 & 26 \\
\hline Ag/PEDOT:PSS-MoO$/{ }_{3} / \mathrm{n}-\mathrm{Si} / \mathrm{In}: \mathrm{Ga}$ & 25 & 29.4 & 0.552 & 0.683 & 11.01 & 2013 & 32 \\
\hline $\mathrm{LiF} / \mathrm{PCBM} / \mathrm{i}-\mathrm{Si} / \mathrm{p}-\mathrm{Si} / \mathrm{FTO} / \mathrm{Glass}$ & - & 15.94 & 0.81 & 0.64 & 8.34 & 2013 & 31 \\
\hline Ag/PEDOT:PSS/n-Si/Liq/Al & 80 & 28.3 & 0.609 & 0.71 & 12.2 & 2014 & 28 \\
\hline $\mathrm{Au} / \mathrm{PEDOT}: \mathrm{PSS} / \mathrm{n}-\mathrm{Si} / \mathrm{In}: \mathrm{Ga}$ & 81.0 & 29.6 & 0.619 & 0.69 & 12.6 & 2014 & 37 \\
\hline Ag/PEDOT:PSS-EG/n-Si/Al & 36 & 32.6 & 0.564 & 0.724 & 13.3 & 2014 & 35 \\
\hline $\mathrm{Ag} / \mathrm{MoO}_{3} / \mathrm{PEDOT}: \mathrm{PSS} / \mathrm{n}-\mathrm{Si} / \mathrm{Liq} / \mathrm{Al}$ & 80 & 29.2 & 0.630 & 0.749 & 13.8 & 2014 & 29 \\
\hline
\end{tabular}

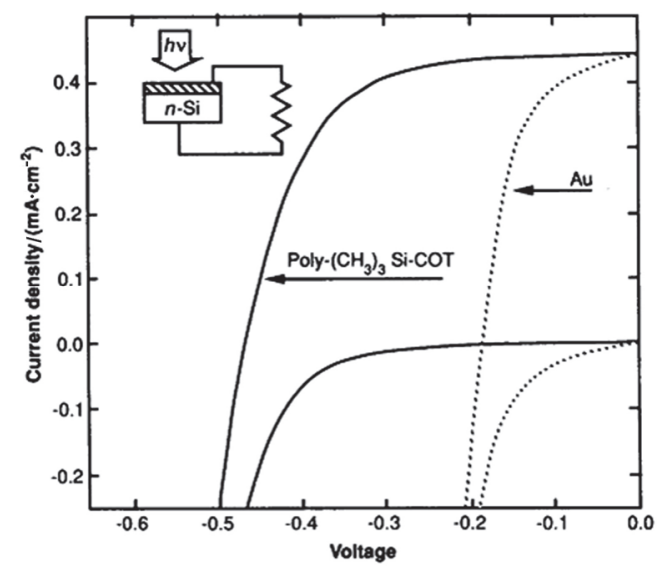

图 3 聚-硅甲基-环四辛基/n-硅(实线)和金 $/ \mathrm{n}$-硅(虚线)太阳能电池在 暗态和光照下的 $J-V$ 特性曲线 ${ }^{[6]}$

Figure $3 \mathrm{~J}-\mathrm{V}$ characteristics of the hybrid poly- $\left(\mathrm{CH}_{3}\right)_{3} \mathrm{Si}$ cyclooctatetraene/n-Si hybrid solar cell and a $\mathrm{Si} / \mathrm{Au} \mathrm{MS}$ solar cell under illumination and in the $\operatorname{dark}^{[6]}$

\section{1 平面硅基杂化太阳能电池的早期研究}

2000 年, $\operatorname{Riad}$ 利用热蒸镀的方法在 $\mathrm{n}-\mathrm{Si}$ 上沉积了一 层 $\mathrm{p}$-型的酞菁镁 $(\mathrm{p}-\mathrm{MgPc})$ 形成异质结器件, 暗态下测量 其电容一电压特性研究 $\mathrm{MgPc}$ 界面处的势垒区域, 并且 在 $50 \mathrm{~mW} / \mathrm{cm}^{2}$ 光强下用 $633 \mathrm{~nm}$ 单色光照射, 产生了 $0.35 \mathrm{~V}$ 开路电压, $3.57 \mathrm{~mA} / \mathrm{cm}^{2}$ 电流和 $1.05 \%$ 的效率 ${ }^{[20]}$. 该器件还得到了 $2.2 \times 10^{16} \mathrm{~cm}^{-3}$ 的自由载流子浓度和 75 $\mathrm{nm}$ 的势垒宽度. 2005 年, Jabbour 等仿照 p-i-n 电池的概 念, 将 $\mathrm{p}$-型的 $\mathrm{a}-\mathrm{SiC}: \mathrm{H}: \mathrm{B}$ 层换成旋涂有机的 PEDOT: $\mathrm{PSS}^{[21]}$, 制备了薄膜杂化太阳能电池(如图 4 所示). 为了 增加 PEDOT:PSS 的导电性, 他们掺入了甘油, 甲基吡 咯烷酮和异丙醇三种物质, 然后旋涂到 ITO 基底上, 在 $110 \mathrm{~nm}$ 的薄膜大约有 $2.5 \mathrm{k} \Omega / \mathrm{sq}$ 的串联电阻, 然后转移 到热蒸镀的腔体中分别沉积无定型硅 a-Si:H, 多晶硅 $\mu \mathrm{c}-\mathrm{Si}(\mathrm{i}), \mu \mathrm{c}-\mathrm{Si}(\mathrm{n})$ 以及电极钯( $\mathrm{Pd})$. 该电池产生了高达
$0.88 \mathrm{~V}$ 的开路电压, 0.51 的填充因子以及 $2.55 \mathrm{~mA} / \mathrm{cm}^{2}$ 的短路电流, 最终产生 $2.1 \%$ 的效率. 在对各层厚度进行 优化之后, 他们采用了理论模拟, 将 PEDOT:PSS 作为 和 a-Si:H 相似的半导体, 计算得出其带隙大约为 $1.7 \mathrm{eV}$, 研究了电池得到的高开路电压的原因, 而界面因素如 PSS 的影响, 表面针化以及耗尽层的宽度等问题都没有 涉及. 同年, Abd-El-Rahman 等报道了酞菁镍 $(\mathrm{NiPc}) / \mathrm{n}-\mathrm{Si}$ 结构的杂化太阳能电池, NiPc 用热蒸镀沉积到硅基底上, 并采用了 $100{ }^{\circ} \mathrm{C}$ 下退火 $2 \mathrm{~h}$ 的工艺, 在 $6 \mathrm{~mW} / \mathrm{cm}^{2}$ 白光 照射下光电转换效率是 $1.11 \%{ }^{[22]}$, 之后在 $\mathrm{n}-\mathrm{Si}$ 上热蒸镀 了一层四苯基卟啉(TPP)和苯胺类物质 TCVA, 两种器 件分别产生了 $2.45 \%$ 和 $3.1 \%$ 的转换效率 ${ }^{[23]}$.

虽然这些杂化太阳能电池的效率并没有取得很大 突破, 但是有机一无机的制备方法已经开始引起人们的 关注，同时退火和掺杂等工艺的开发也为以后杂化太阳 能电池的效率提升打下了重要的基础. 利用酞菁类和 TPP 等制备的电池得到了可观的开路电压, 但是由于这 些有机物的导电性和结晶性比无机半导体差了几个数 量级, 并且器件制备的工艺也没有进行最优化, 机理正 处于探索阶段, 在器件性能上体现为短路电流和填充因 子比较差. 经过近几年的发展, 许多电导率很高的半导 体有机物纷纷出现, 如已经商业化的 P3HT 和 PEDOT:PSS, 具有优异的电学和光学性能. 利用这些高 性能有机物, 许多课题组已经制备出了效率超过 $10 \%$ 的 硅基杂化太阳能电池 ${ }^{[24 ~ 29]}$, 目前报道的基于硅的最高 转化效率已经达到 $13.8 \%{ }^{[29]}$.

2007 年, Wang 等在 $n-S i$ 上旋涂了用酸掺杂的不同 电导率的聚苯胺(PANI), 发现当薄膜的电导率在 $10^{-1}$ $\mathrm{S} / \mathrm{cm}$ 以下时, 开路电压受薄膜的功函数限制, 会随着电 导率的上升而增加 ${ }^{[30]}$. 通过理论计算表明, PANI 薄膜理 论上可以产生 $0.7 \mathrm{~V}$ 以上的开路电压, 几乎可以与硅异 质结电池(Heterojunction with Intrinsic Thin Layer, HIT) 
表 2 基于硅微纳结构的杂化太阳能电池光伏性能

Table 2 Photovoltaic properties of micro/nano structure-based silicon based hybrid solar cell

\begin{tabular}{|c|c|c|c|c|c|c|c|}
\hline Device Structure & Area $/ \mathrm{mm}^{2}$ & $J_{\mathrm{sc}} /\left(\mathrm{mA} \cdot \mathrm{cm}^{-2}\right)$ & $V_{\text {oc }} / \mathrm{V}$ & $\mathrm{FF}$ & $\mathrm{PCE} / \%$ & Year & Ref. \\
\hline ITO/PEDOT:PSS/SiNWs & - & 19.28 & 0.47 & 0.61 & 5.09 & 2010 & 45 \\
\hline ITO/PEDOT:PSS/SiNWs/Al & - & 21.6 & 0.46 & 0.64 & 6.35 & 2011 & 46 \\
\hline Ag/PEDOT:PSS/SiNWs/Al & 100 & 26.3 & 0.53 & 0.642 & 9.0 & 2011 & 47 \\
\hline $\begin{array}{l}\mathrm{Ag} / \mathrm{Cu} / \mathrm{PEDOT}: \mathrm{PSS} / \mathrm{Cu} / \text { spiro-OMeTAD } \\
\text { /SiNWs/In:Ga }\end{array}$ & 80 & 31.3 & 0.527 & 0.588 & 9.7 & 2011 & 48 \\
\hline Ag/Spiro-OMeTAD/SiNWs/Al & 95 & 30.72 & 0.57 & 0.724 & 9.92 & 2012 & 50 \\
\hline Ag/PEDOT:PSS/SiNWs/Si Pyramid/Al & 100 & 31.4 & 0.53 & 0.593 & 9.9 & 2012 & 66 \\
\hline ITO/PEDOT:PSS/SiNP/ $\mathrm{Al}_{2} \mathrm{O}_{3} / \mathrm{Ni} / \mathrm{Ag}$ & 100 & 30.1 & 0.578 & 0.71 & 10.56 & 2013 & 52 \\
\hline Ag/PEDOT:PSS/SiNWs/Si Pyramid/Al & - & 34.46 & 0.52 & 0.64 & 11.48 & 2013 & 27 \\
\hline Ag/PEDOT:PSS/TAPC/SiNWs/Al & 25 & 34.76 & 0.54 & 0.695 & 13.01 & 2013 & 53 \\
\hline Ag/PEDOT:PSS/Si Nanotube/Al & 100 & 29.9 & 0.51 & 0.657 & 10.03 & 2014 & 67 \\
\hline Au/PEDOT:PSS/Si Nanocone/Al & - & 29.6 & 0.55 & 0.677 & 11.1 & 2012 & 25 \\
\hline AgNW/PEDOT:PSS/Si Pyramid/Al & - & 28.5 & 0.53 & 0.669 & 10.1 & 2012 & 63 \\
\hline Ag/PEDOT:PSS/Si Pyramids/Al & 400 & 32.5 & 0.48 & 0.696 & 10.86 & 2013 & 64 \\
\hline Au/P3OT:MWNTs/SiNWs/Al & - & 7.85 & 0.353 & 0.22 & 0.61 & 2009 & 56 \\
\hline ITO/PEDOT:PSS/P3HT:PCBM:SiNWs/Al & 15 & 11.61 & 0.425 & 0.39 & 1.91 & 2009 & 58 \\
\hline $\mathrm{Cu} / \mathrm{P} 3 \mathrm{HT}: \mathrm{Pt} / \mathrm{SiNW} / \mathrm{Ga}: \mathrm{In}$ & 30 & 26.2 & 0.421 & 0.53 & 5.9 & 2011 & 60 \\
\hline ITO/PEDOT:PSS/Si NCs:P3HT/Al & - & 3.3 & 0.75 & 0.46 & 1.15 & 2008 & 68 \\
\hline ITO/Si NCs:PTB7/PEDOT:PSS/Al & 4.6 & 9.97 & 0.579 & 0.389 & 2.25 & 2014 & 70 \\
\hline
\end{tabular}

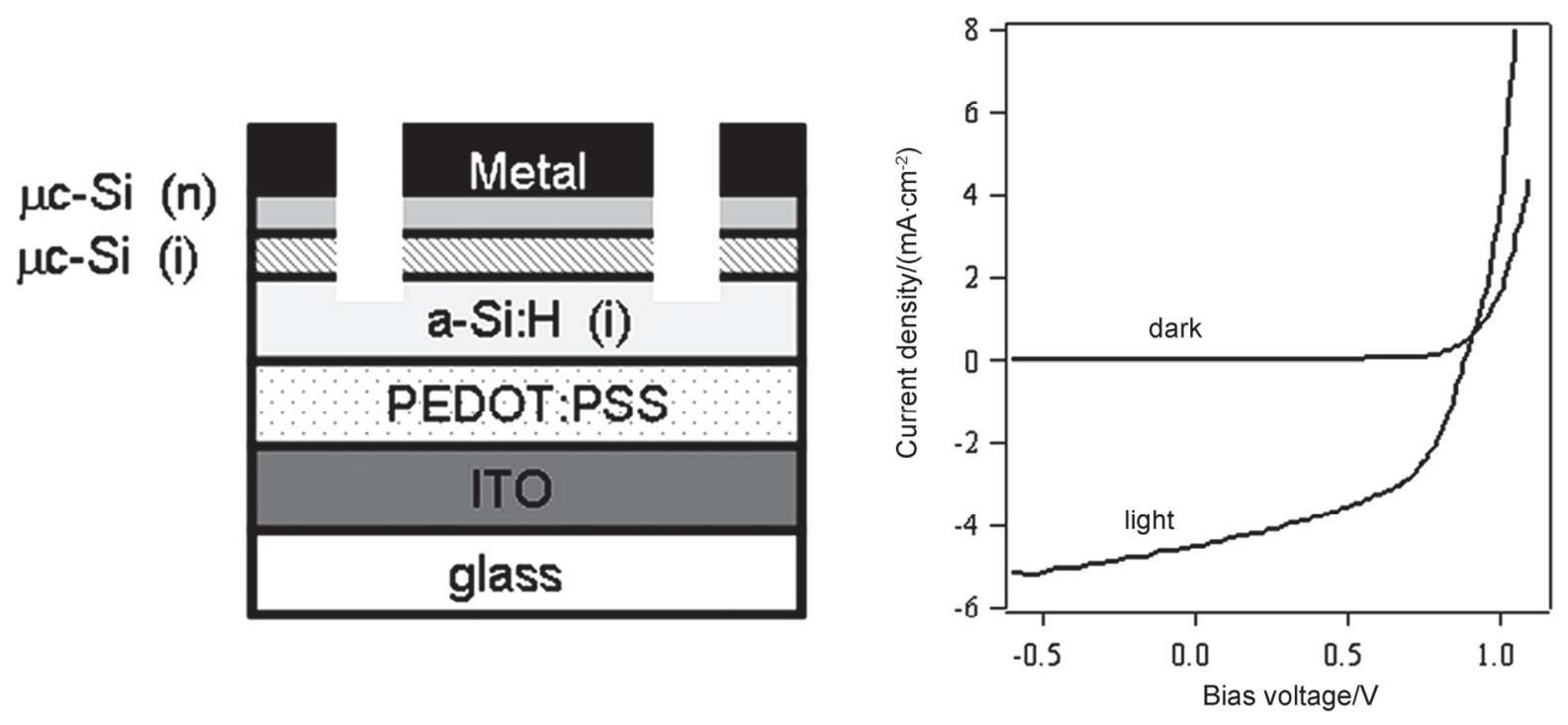

图 $4 \mathrm{Pd} / \mathrm{n}-\mathrm{Si} / \mathrm{i}-\mathrm{Si} / \mathrm{i}-\mathrm{Si}: \mathrm{H}(\mathrm{a}) / \mathrm{PEDOT}: \mathrm{PSS} / \mathrm{ITO} / \mathrm{Glass}$ 薄膜杂化太阳能电池的器件结构图(左图)和在光照及暗态的 $J-V$ 特性曲线(右图) ${ }^{[21]}$

Figure 4 Device structure (left) and $J-V$ characteristics (right) of a Pd/n-Si/i-Si/i-Si:H(a)/PEDOT:PSS/ITO/Glass thin film hybrid solar cell ${ }^{[21]}$

的开路电压极值相当, 该器件在 $0.1 \mathrm{~W} / \mathrm{cm}^{2}$ 光照下产生 了 $0.51 \mathrm{~V}$ 的开路电压, $17 \mathrm{~mA} / \mathrm{cm}^{2}$ 的短路电流, 最终效率 为 $3.35 \%$. 电流相对于以前报道数值的大幅度提升主要 是得益于 PANI 优异的电导率, 能够更有效地传输空穴, 但是因为没有制备顶部金属栅极, 其横向传输电荷的效 果比较差, 界面也没有经过优化, 所以填充因子比较低 (41\%).

对于有机物而言, 进一步的研究表明, 考虑到能带 匹配和更有效的载流子收集, 需要满足这些条件: (1)其
可调的最高占有分子轨道能级(HOMO) 和硅的价带之间 的差值必须足够小, 减小空穴传输的势垒, 以取得更高 的电流; (2)其最低未占分子轨道(LUMO)能级和硅的导 带之间的差值足够大，以产生更高的开路电压. P3HT 刚 好满足这些条件, 其 HOMO 和 LUMO 分别为 $5.1 \mathrm{eV}$ 和 $3.2 \mathrm{eV}$, 而硅的价带 $\left(E_{\mathrm{v}}\right)$ 和导带 $\left(E_{\mathrm{c}}\right)$ 分别为 $5.17 \mathrm{eV}$ 和 4.05 $\mathrm{eV}$. 以此得到在硅和 P3HT 的界面上, $E_{\mathrm{c}}$ 和 LUMO 差值 约为 $0.8 \mathrm{eV}, E_{\mathrm{v}}$ 和 $\mathrm{HOMO}$ 几乎相当. 同时 $\mathrm{P} 3 \mathrm{HT}$ 的薄膜 体迁移率可达到约 $10^{-4} \mathrm{~cm}^{2} /(\mathrm{V} \cdot \mathrm{s})$. 在建立了条件分析 
之后, Sturm 等 ${ }^{[24]}$ 又对电极进行了优化, 在旋涂 $10 \mathrm{~nm}$ 的 P3HT 薄膜之后, 在上面再旋涂了 $80 \mathrm{~nm}$ 厚的 PEDOT: PSS 薄膜以加强对电荷的收集, PEDOT:PSS 电导率虽然 不足以取代金属电极, 但是其良好的透光性却可以保证 金属栅线所占的面积最小化, 之后再在上面蒸镀了 $\mathrm{Pd} / \mathrm{Ag}$ 栅极. 材料的选择和对电极结构的优化使得该器 件的效率达到了突破性的 $10.1 \%, 29 \mathrm{~mA} / \mathrm{cm}^{2}$ 的短路电流 仅仅比硅的极限电流 $42 \mathrm{~mA} / \mathrm{cm}^{2}$ 少 $30 \%$ (如图 5 所示). Kim 等 ${ }^{[31]}$ 采用了类似的思路, 将 PCBM 用作空穴阻挡 层, 在 $\mathrm{p}$-型硅上制备了杂化太阳能电池, 并得到 $8.34 \%$ 的效率. 这些有机物/平面硅电池的器件结构及器件性 能在表 1 进行了总结.

\section{2 对杂化太阳能电池中 PEDOT:PSS 的改性研究}

在有机/无机杂化太阳能电池中, 为了得到更高的 短路电流, 必须让硅吸收足够的入射光, P3HT 虽然有着 理想的能带结构, 但是其在可见及红外区域对光有一定 的吸收, 并且随着厚度的增加而增加, 最终对更高的效 率会产生不利的影响. 目前最受关注的另一种典型的商 业化共轭导电聚合物 PEDOT:PSS 具有很好的成膜性和 透光性, 在可见光区域内几乎不吸收光, 同时也有良好 的导电性和稳定性, 接近硅价带的功函数. 使其成为理 想的异质结接触材料. 对于有机物本身而言, 许多方法 被用于改善其导电性, 分散性, 功函数等以提高器件的 性能. 2012 年, Shirai 等在 PEDOT:PSS 中掺入了含氟的 表面活性剂 Zonly ${ }^{[26]}$, 增强了有机物在氢化的硅片表面 的粘附力, 降低了界面处的电子复合, 得到了 $11.34 \%$ 的 最高效率. 他们也研究了在 PEDOT:PSS 中掺杂 $\mathrm{MoO}_{3}$ 可以修饰其分子结构 ${ }^{[32 \mathrm{a}]}$, 从而提高结的载流子收集效 率, 取得了 $11.01 \%$ 的效率, 而未掺杂的器件效率为 9.89\%. Sun 课题组等在 PEDOT:PSS 中添加了一种全氟 的离子聚合物 $\mathrm{PFI}^{[32 \mathrm{~b}]}$, 利用后者的强电子吸引力来调节 PEDOT:PSS 的功函数, 从而提高了内建电场, 降低了界 面载流子复合速率, 得到了 $70 \%$ 的填充因子. Bashouti 等则研究了 PEDOT:PSS 的核壳结构 ${ }^{[33]}$, 认为外层的



PSS 对载流子的传输和分离有一定的势垒作用，影响到 薄膜的导电性和电池的开路电压, 通过添加 DMSO 能 够移除多余的 PSS, 使得 PEDOT:PSS 可以更好地分散 在溶剂中, 从而提高其薄膜的载流子传输能力. Sun 等 则利用低串联电阻和高功函数的二维 $\operatorname{CoS}^{[34]}$, 通过调节 $\mathrm{CoS}$ 在薄膜中的形貌和浓度，降低了界面的复合速率， 电池效率超过 $11 \%$. Thomas 等 ${ }^{[35]}$ 在 PEDOT:PSS 里同时 添加了乙二醇(EG)和含氟类的表面活性剂(FS300), 通 过三维化学组分图像发现 PEDOT:PSS 和硅界面处的缺 陷达到了一个极低的数值, 同时薄膜的串联电阻也大大 降低, 反射率也有一定下降, 在平面硅为基底的杂化太 阳能电池上得到了 $32.6 \mathrm{~mA} / \mathrm{cm}^{2}$ 的短路电流, 以及高达 $13.3 \%$ 的转化效率.

\section{3 对 Si/PEDOT:PSS 杂化太阳能电池的结构探索和 优化}

PEDOT:PSS 通常被作为一种类似金属的半导体, 其与硅接触形成的结一般被认为属于肖特基结, Cahen 等 ${ }^{[36]}$ 则通过使用不同磷原子掺杂浓度的 $\mathrm{n}$ 型硅片制备杂 化太阳能电池, 认为载流子分离的源动力是硅的内建电 场, 与肖特基结的机理不同. 他们认为该器件属于一种 类似 $\mathrm{p}-\mathrm{n}$ 结的反向太阳能电池(Inversion Layer Solar Cell), 提高器件性能的途径包括界面钝化, 调节有机物 的功函数以增加能带弯曲和提高载流子分离. Pietsch 等 ${ }^{[37}$ 也通过采用不同掺杂浓度的硅片，在最高掺杂浓度 的器件中取得了 $0.645 \mathrm{~V}$ 的开路电压和 $12.6 \%$ 的转化效 率. 硅和金属的直接接触通常带来严重的界面复合问 题, 降低器件性能, Sun 课题组 ${ }^{[28,38]}$ 在金属电极蒸镀到硅 片上之前先蒸了一层 $2 \mathrm{~nm}$ 的 8-差基喹啉-锂( $\mathrm{Liq}$ )或者 LiF，它们和金属形成负的表面偶极区域，有利于电子 传输和空穴阻挡(如图 6 所示). 对背电极的优化使电池 得到了 $0.609 \mathrm{~V}$ 的开路电压, $28.3 \mathrm{~mA} / \mathrm{cm}^{2}$ 的短路电流, $71 \%$ 的填充因子和 $12.2 \%$ 的最优效率. 为了解决平面硅 电流比较低的缺陷, 他们通过在 PEDOT:PSS 上热蒸镀 一层高功函数的 $\mathrm{MoO}_{3}$ 薄膜(如图 7 所示), 在硅片上面形

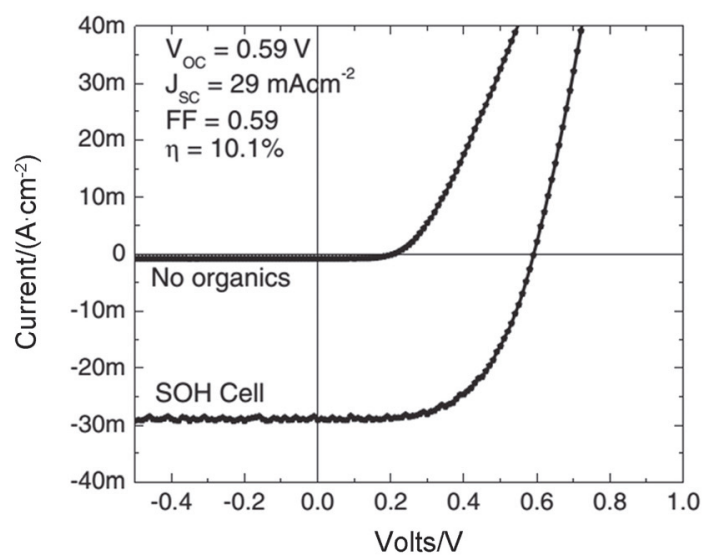

图 $5 \mathrm{Pd} / \mathrm{Ag} / \mathrm{EPDOT}: \mathrm{PSS} / \mathrm{P} 3 \mathrm{HT} / \mathrm{n}-\mathrm{Si} / \mathrm{Al}$ 的器件结构图(左图)和在光照及暗态 $J-V$ 特性曲线(右图) ${ }^{[24]}$

Figure 5 Device structure (left) and $J-V$ characteristics (right) of a Pd/Ag/EPDOT:PSS/P3HT/n-Si/Al hybrid solar cell ${ }^{[24]}$ 




(b)

PEDOT:PSS
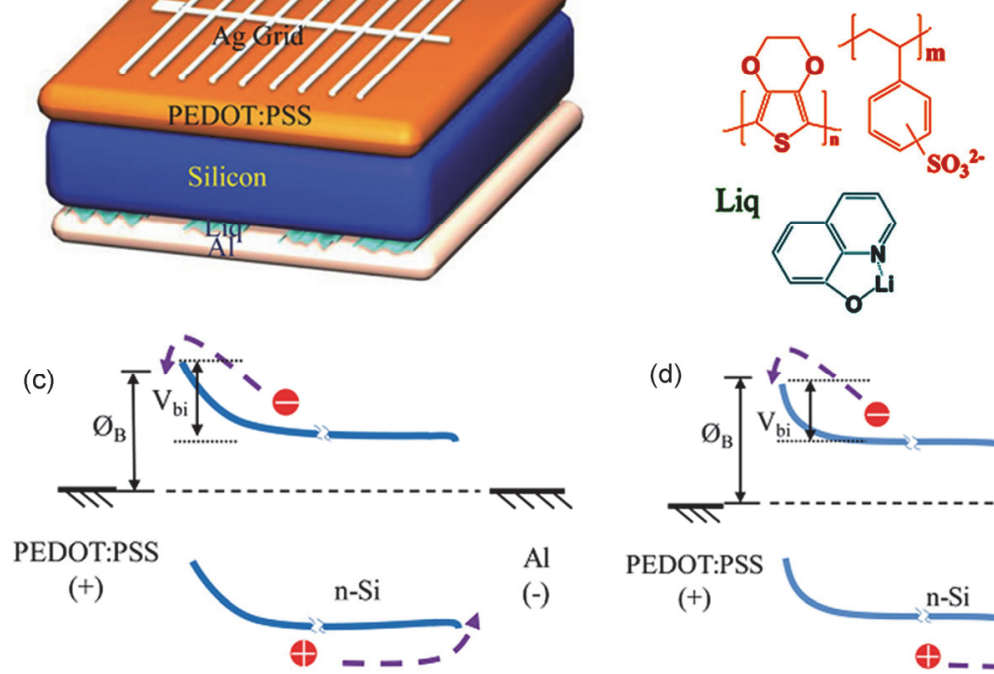

Liq


图 6 用 $\mathrm{Liq} / \mathrm{Al}$ 复合电极作为背电极的 Si/PEDOT:PSS (a) 器件结构示意图, (b) PEDOT:PSS 及 Liq 的化学结构式, (c) 没有(d)有 Liq 层的器件能带 图 $^{[28]}$

Figure 6 (a) Device structure, (b) molecular structure of PEDOT:PSS and Liq, and band diagram of Si/PEDOT:PSS hybrid solar cell without (c) and with (d) $\mathrm{Liq} / \mathrm{Al}$ as rear contact $^{[28]}$

(a)
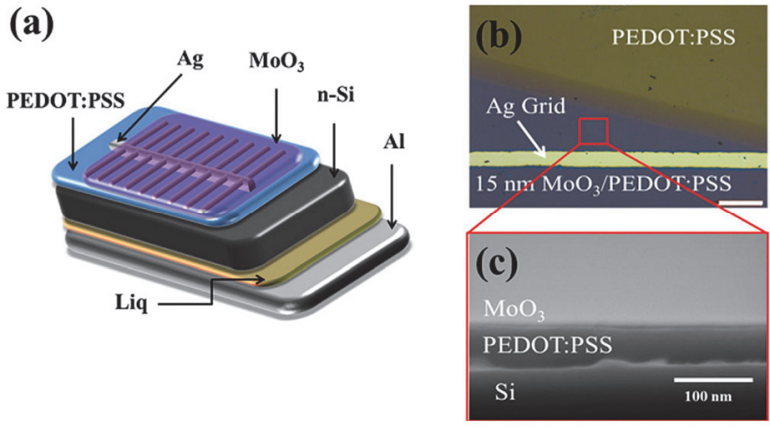

图 7 (a) $\mathrm{MoO}_{3} / \mathrm{Ag} / \mathrm{PEDOT}: \mathrm{PSS} / \mathrm{n}-\mathrm{Si} / \mathrm{Liq} / \mathrm{Al}$ 器件结构图, (b)有/无 $\mathrm{MoO}_{3}$ 层的 SEM 平面和(c)截面图 ${ }^{[29]}$

Figure 7 (a) Device structure of the $\mathrm{MoO}_{3} / \mathrm{Ag} / \mathrm{PEDOT}: \mathrm{PSS} / \mathrm{n}-\mathrm{Si} / \mathrm{Liq} / \mathrm{Al}$ hybrid solar cells, (b) Optical image of the Si/PEDOT:PSS cell with (bottom left) and without (top right) $\mathrm{MoO}_{3}$ layer, (c) Cross-sectional SEM image of the cell with 15 -nm-thick $\mathrm{MoO}_{3}{ }^{[29]}$

成了 $\mathrm{MoO}_{3} / \mathrm{PEDOT}: \mathrm{PSS}$ 双层减反薄膜, 提高了短路电 流; 同时高功函的 $\mathrm{MoO}_{3}$ 又提高了 PEDOT:PSS 的功函 数, 在硅上产生了一层反向层, 减少了复合, 提高了开 路电压. 经过光学和电学的优化, 该电池的开路电压达 到了 $0.63 \mathrm{~V}$, 短路电流为 $29.2 \mathrm{~mA} / \mathrm{cm}^{2}$, 填充因子为 $74.9 \%$, 得到了目前有机/硅杂化太阳能电池的最高效率 $13.8 \%{ }^{[29]}$.

\section{0 基于硅微纳结构的有机-无机杂化太阳能电池}

平面硅和有机物可以形成很好的电学接触, 当选择 了合适的有机物以及对其进行改性处理, 以及对电极的 优化实现更优异电学传输和接触性能之后, 器件可以得 到较高的开路电压和填充因子, 但是杂化太阳能电池的 效率并没有和晶硅电池相当. 限制杂化电池性能提升的 主要因素就在于对太阳光的吸收能力, 平面硅对太阳光 高达 $30 \%$ 的反射率使得绝大部分这种电池的短路电流
都在 $30 \mathrm{~mA} / \mathrm{cm}^{2}$ 以下，与传统方法制备的晶硅电池的短 路电流 $42 \mathrm{~mA} / \mathrm{cm}^{2}$ 仍有极大的差距. 利用硅的微纳结构 就是降低硅片表面反射，进而提高短路电流的有效方 法. 硅的纳(微)米线、孔、锥、金字塔等表面不仅能对 光进行减反和散射作用从而提高吸光能力, 其大的比表 面积也提供了更大的结区接触面积, 从而提高载流子的 分离效率，同时也可以减少材料的使用和对硅纯度的依 赖. 一个表面制备了纳米结构的 “黑硅” 电池 ${ }^{[39]}$ 在没有 制备减反层的条件下取得了 $36.45 \mathrm{~mA} / \mathrm{cm}^{2}$ 的短路电流 和 $18.2 \%$ 的转化效率, 与制备减反层的工业电池性能相 当. 在硅基杂化太阳能电池中, 利用硅结构也取得了显 著进展, 显示出了广阔的研究前景(详见表 2).

\section{1 基于硅纳米线的杂化太阳能电池}

在众多硅结构中, 硅纳米线(SiNWs)不仅有出色的 陷光能力, 其独特构造形成的核壳结构能够给载流子提 供更短传输路径的径向通道，从而提高电池的性能; 载 流子传输路径的缩短又能够克服低纯度硅片载流子迁 移率较低的缺陷，降低了硅片的制作成本. 硅纳米线阵 列可以通过 “自下而上” 的金属颗粒汽-液-固(VLS), 化 学气相生长 $(\mathrm{CVD})^{[40]}$ 和 “自上而下” 的金属辅助催化湿 法刻蚀(MACE) ${ }^{[41,42]}$, 离子反应刻蚀(RIE) ${ }^{[11]}$ 等方法制备, 后者因为工艺的简便以及对硅线晶型的良好控制得到 了广泛的应用. 利用单根的硅纳米线或者硅纳米线阵列 制备的硅 p-n(p-i-n)结太阳能电池首先引发了许多研 究 ${ }^{[9,10,43,44]}$, 理论研究表明利用硅纳米线结构的电池采 用不同的尺寸和质量可获得 $15 \% \sim 18 \%$ 的转化效率. 但 是通过这种方法制备的硅纳米线电池需要经受高温处 理过程 $\left(\sim 1000{ }^{\circ} \mathrm{C}\right)$, 带来了金属离子杂质的掺入, 会降 低器件的少数载流子寿命, 这种效应在高比表面积的硅 
纳米线中更加显著, 界面处的剧烈复合对电池性能产生 不利的影响, 所以目前该类器件的效率并没有取得很大 突破, 而在低温过程中形成的有机/无机异质结则克服 了这个问题.

在硅纳米线杂化光伏器件中, PEDOT:PSS 也是得到 最广泛研究的有机材料. 2010 年 Lin 等 ${ }^{[45]}$ 通过将纳米线 压印在旋涂了 PEDOT:PSS 的 ITO 基底上, 首先制备出 了 SiNW/PEDOT:PSS 核壳异质结杂化太阳能电池(如图 8 所示), 通过增加结区面积和减小载流子传输距离, 大 大提高了载流子的收集效率. 他们发现在硅纳米线上的 电池串联电阻为 $1.47 \Omega \cdot \mathrm{cm}^{2}$, 在平面硅上的为 60.42 $\Omega \cdot \mathrm{cm}^{2}$, 效率从平面硅电池的 $0.08 \%$ 增加到 $5.09 \%$, 而同 期的硅纳米线 $\mathrm{p}-\mathrm{n}$ 结太阳能电池效率因为上述问题效率 大都在 $1 \%$ 以下. 硅纳米线阵列在 $400 \sim 1100 \mathrm{~nm}$ 波段的 反射率都在 $5 \%$ 以下, 使得电池的短路电流从平面硅的 $1.27 \mathrm{~mA} / \mathrm{cm}^{2}$ 提升到了 $19.28 \mathrm{~mA} / \mathrm{cm}^{2}$. 而 Chen 课题组 ${ }^{[46]}$ 则直接将 PEDOT:PSS 旋涂在硅纳米线阵列上, 在有机 物里面添加了乙醇以减小表面张力, 获得更多的接触界 面, 将效率提升到了 $6.35 \%$. 通过优化硅纳米线的长度, Lai 等 ${ }^{[47]}$ 在硅纳米线长度为 $900 \mathrm{~nm}$ 的器件中取得了 $9 \%$ 的效率. 因为共轭有机物较长的分子链和大的表面张 力, 它们往往无法进入硅纳米线之间的间距, 结区不能 更有效地进行接触. Sun 课题组 ${ }^{[48]}$ 通过甲基化的方法来

(a)
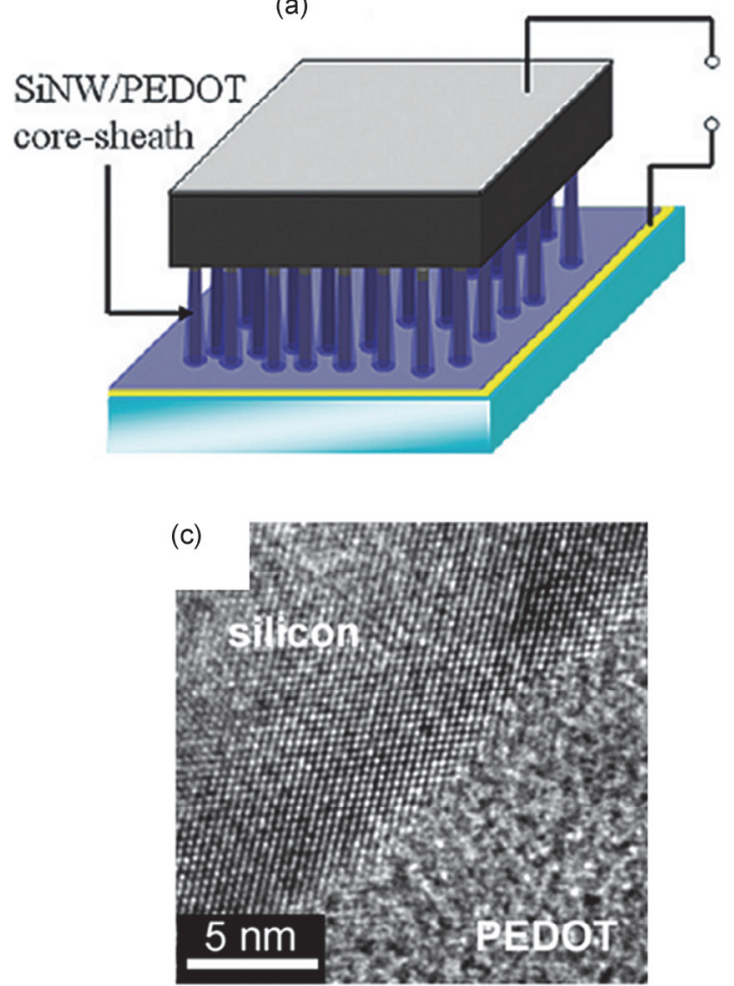

钝化硅纳米线表面，同时调控纳米线的密度，在硅纳米 线阵列上面旋涂小分子 Spiro-OMeTAD 以实现良好的界 面接触，再旋涂一层 PEDOT:PSS 以保证电荷的收集以 及和金属电极的更好接触(如图 9 所示). 在优化了小分 子层和电极界面层的厚度之后, 器件的效率达到了 9.7\%，另一个课题组也发表了类似的工作并取得 10\%的

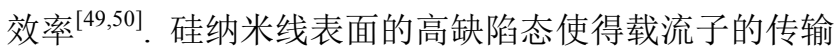
受到很大影响, 而通过一般金属离子辅助化学刻蚀得到 的硅纳米线的密度过大 $\left(\sim 5 \times 10^{9}\right)$, 不利于有机物的填 充. Sun 课题组 ${ }^{[51]}$ 就使用了一种简单的化学刻蚀方法将 纳米线的密度减小, 提高了器件中载流子的分离和传 输. 瞬态光电压和暗电流的拟合表明，电荷在界面处的 复合极大影响着杂化光伏器件的效率，通过甲基和丙烯 基单分子层对硅纳米线表面的钝化，实现了 $10.2 \%$ 的效 率. 对于界面复合问题，有报道使用原子层堆积法在短 硅线表面和 PEDOT:PSS 之间沉积了一层薄的氧化铝作 为钝化层 ${ }^{[52]}$, 将开路电压从 $0.53 \mathrm{~V}$ 提高到 $0.58 \mathrm{~V}$, 器件 效率从 $9.65 \%$ 提高到了 $10.56 \%$. Yu 等在硅纳米线和 PEDOT:PSS 之间旋涂了一层 4,4'-环己基二[ $N, N$-二(4-甲 基苯基)苯胺](TAPC) ${ }^{[53]}$ (如图 10 所示). TAPC 在电池中 主要起三个作用: (1)修饰 PEDOT:PSS 在硅纳米线上的 形貌，使其更好地铺展; (2)通过势垒抑制了反向饱和电 流，从而提高电压; (3)减缓界面处的氧化. 通过这种表


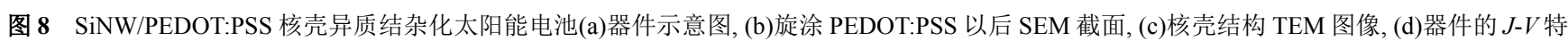
性曲线 $[45]$

Figure 8 (a) Device structure, (b) Cross-section SEM image of the PEDOT:PSS coated SiNW, (c) TEM image of the PEDOT:PSS coated SiNW, (d) $J$ - $V$ characteristics of a core-shell SiNW/PEDOT:PSS hybrid cell ${ }^{[4]}$ 

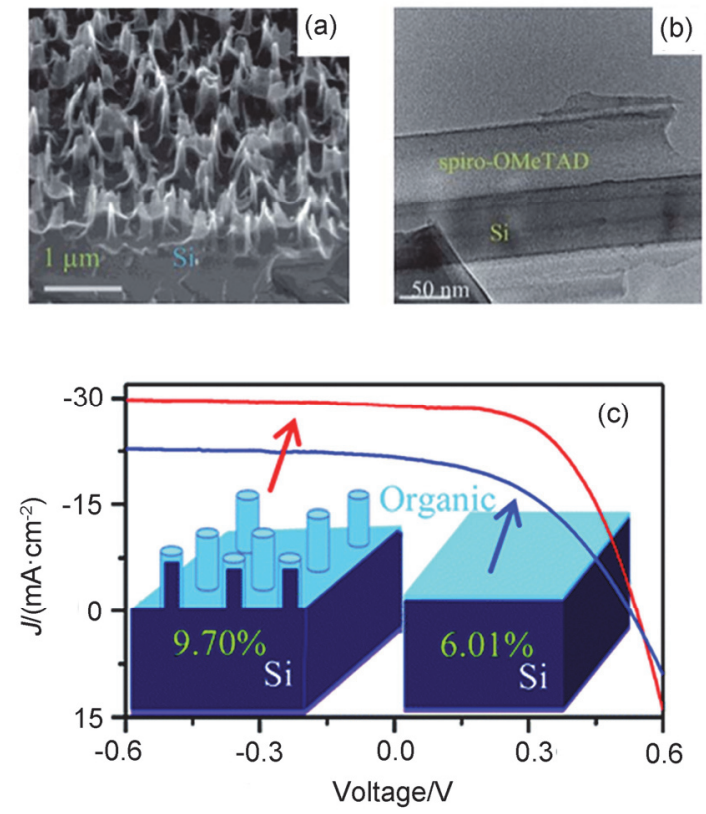

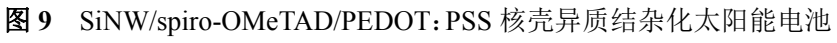
(a) 核壳结构 SEM 截面图, (b)TEM 图像, (c) 器件的 $J-V$ 特性曲线 ${ }^{[8]}$ Figure 9 (a) Cross-section SEM image of the SiNW, (b) TEM image of the Spiro-OMeTAD coated SiNW, (c) $J-V$ characteristics of the Coreshell hybrid solar cell ${ }^{[48]}$

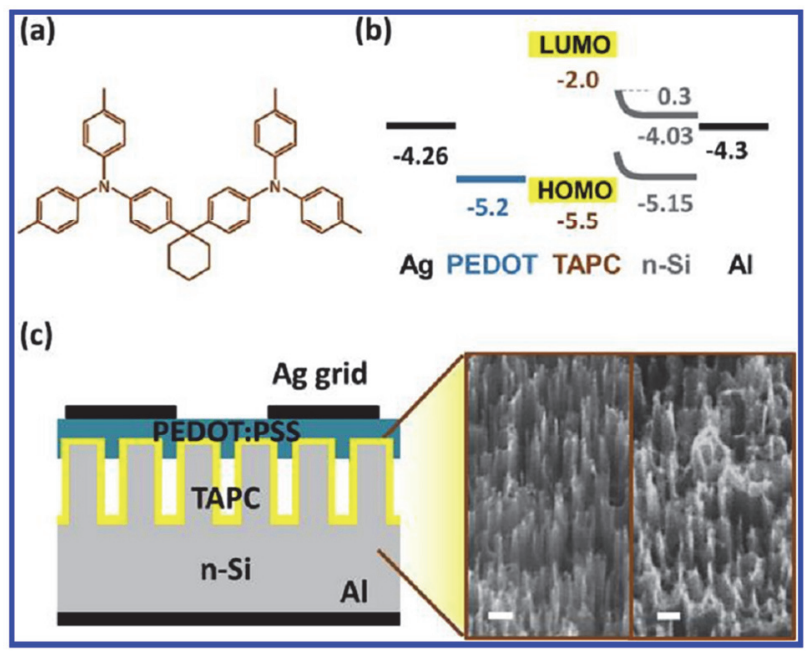

图 $10 \mathrm{TAPC}$ 分子结构图, 器件能带图和示意图, 以及界面处 SEM 形 貌 ${ }^{[33]}$

Figure 10 The molecule structures of TAPC, the device structure and cross-section SEM image of SiNW/TAPC hybrid solar cell ${ }^{[53]}$

面处理方法提高了开路电压和填充因子, 器件效率达到 了 $13.01 \%$, 是目前报道的基于硅微纳结构杂化太阳能 电池的最高效率, 说明了界面在太阳能电池中的关键性 作用. 在最近的报道中, 已经有杂化光伏器件使用超薄 的柔性硅片作为基底 ${ }^{[5,55]}$, 采用硅纳米线作为吸光结 构, 在 $60 \mu \mathrm{m}$ 厚的硅基底上取得了 $36.81 \mathrm{~mA} / \mathrm{cm}^{2}$ 的短路 电流和 12\%的效率, 这使得低成本高效率的硅基杂化太 阳能电池更受瞩目.

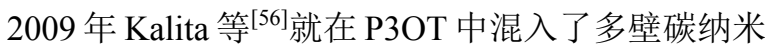
管(MWNTs), 与硅纳米线阵列形成的异质结有着更好
的空穴传输性能，电池效率从没有添加 MWNTs 的 $0.19 \%$ 提升到了 $0.61 \%$. 同年, 有报道在 ITO 上生长出了 垂直取向的硅纳米线阵列, 旋涂 P3HT 和 PCBM 的共混 聚合物制备得到的电池性能远远优于 P3HT 和 PCBM 的 有机电池, 取得了 $0.427 \%$ 的效率 ${ }^{[57]}$. 而 Lin 等 ${ }^{[58]}$ 则将在 硅基底上用湿法化学刻蚀得到的硅纳米线阵列压印到 被加热的 P3HT:PCBM 薄膜中, 再将硅纳米线从基底中 剥离, 得到了垂直 SiNWs 和 P3HT:PCBM 的共混杂化太 阳能电池(如图 11 所示), 效率达到了 1.91\%. 这种状态 的硅纳米线能够为电子的传输提供无阻碍的通道, 也为 激子的分离提供了更大的面积，同时也具有可在同一硅 片上重复制取纳米线的优点. 2011 年 Eisenhawer 等 ${ }^{[59]}$ 则先将硅纳米线剥离下来, 再与 P3HT: PCBM 混合, 实 现了更好的接触优化, 将该电池的效率提升到 $4.165 \%$. 通过在硅纳米线表面用电化学的方法沉积铂的纳米颗 粒, Sun 课题组将 SiNW/P3HT 的杂化器件效率提升了 $70 \%{ }^{[00]}$. 铂纳米颗粒在有机/无机的界面处主要起两个 作用: 填补了未被甲基覆盖针化的硅表面从而降低表面 复合，同时高功函的铂在界面处提高了内建电场，有利 于光生载流子的分离传输. 在经过对硅纳米线的尺寸间 距和采用了石墨烯作为透明电极优化之后, 将 $\mathrm{SiNW} / \mathrm{P} 3 \mathrm{HT}$ 杂化太阳电池的效率从 $5.9 \%$ 提升到了 $9.2 \%$ 和 $10.34 \%{ }^{[61,62]}$.

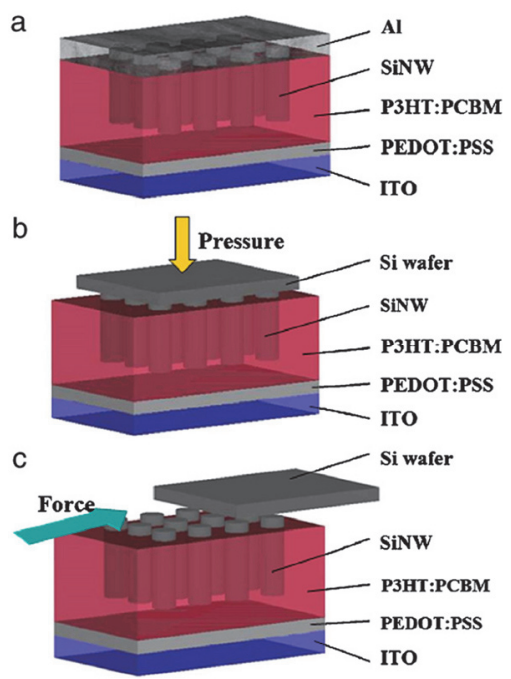

图 11 制备可转移 SiNWs/P3HT:PCBM 共混杂化太阳能电池流程 图 ${ }^{[58]}$

Figure 11 Schematic of hybrid SiNWs/P3HT:PCBM solar cell ${ }^{[58]}$

\section{2 基于其他微纳结构的杂化太阳能电池}

除了硅纳米线之外, 其他的微纳结构同样能够显著 提高电池的电流和转换效率. 采用了微米金字塔结构和 PEDOT: PSS 的杂化太阳能电池取得了 $30.50 \mathrm{~mA} / \mathrm{cm}^{2}$ 的 短路电流和 $9.84 \%$ 的效率 ${ }^{[63]}$, 有课题组用更规整的纳米 压印方法制备的电池在 $4 \mathrm{~cm}^{2}$ 的面积上获得了 32.5 $\mathrm{mA} / \mathrm{cm}^{2}$ 的电流和 $10.86 \%$ 的效率 ${ }^{[64]} .2013$ 年 Schmidt 等 在硅金字塔表面生成了一层自然氧化层以及背面重掺 
形成背场, 在同样的面积上得到了 $12.3 \%$ 的效率 ${ }^{[65]}$. 在 金字塔上面刻蚀硅纳米线既可以增大结区的面积(如图 12), 用短的硅纳米线就可以获得很低的反射率, 硅纳米 线长度的减少能降低表面的复合区域, 这种结构的硅和 PEDOT:PSS 杂化器件的效率也达到了 $10 \%$ $12 \%{ }^{[27,55,66]}$. 采用硅纳米雉, 硅纳米管和 PEDOT:PSS 杂 化的电池效率也分别达到了 $11 \%$ 和 $10 \%{ }^{[25,67]}$.

硅的带隙大约在 $1.1 \mathrm{eV}$, 同时其块体材料间接带隙 的特性也限制了对光的吸收转化, 尺寸在几纳米的硅纳

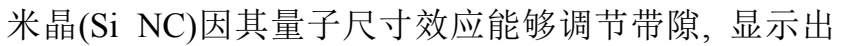
了独特的电学性能. Liu 等 ${ }^{[68]}$ 就制备了 $3 \sim 5 \mathrm{~nm}$ 尺寸的硅 纳米晶, 带隙约为 $1.5 \mathrm{eV}$, 并与 P3HT 共混制备杂化电 池, 观察到了开路电压和短路电流依赖于纳米晶的尺寸 变化, 取得了 $1.15 \%$ 的效率. 之后他们又研究了退火温 度, 时间和金属电极对电池性能的影响并进行了优化, 将效率提升到了 $1.47 \%{ }^{[69]}$. 由于量子尺寸效应带来导带 位置的上移, 器件得到了 $0.8 \mathrm{~V}$ 的开路电压, 超过了 P3HT:PCBM 有机太阳能电池. Ding 等 ${ }^{[70]}$ 比较了 P3HT 和 PTB7 两种有机物与硅纳米晶形成的杂化太阳能电池 的性能, 发现更窄带隙的 PTB7 能吸收更宽的光谱, 同 时将从纳米晶表面的硅氯键替换为硅氢键, 因前者有过 多对器件性能不利的载流子, 表面处理使电池效提高了 3 倍, 在 Si NC: PTB7 杂化太阳能电池中取得了 $2.2 \%$ 的 效率. 这种类型电池效率低下的主要原因是硅纳米晶容 易团聚, 造成形貌的不均匀, 电荷的分离和传输效率低, 电子和空穴的复合比较严重.

除了以上的介绍, 基于硅的有机/无机杂化太阳能 电池方面的研究还有许多优秀的工作, 对于这个领域的 发展做出了重要的贡献 ${ }^{[71]}$. 此外, 在最近几年出现的叠
层杂化太阳能电池也取得了瞩目的研究进展 ${ }^{[72]}$, 通过选 用合适的各层材料，双结电池的开路电压几乎已经实现 了单结电池之和, 多个课题组报道的开路电压超过了 $1.5 \mathrm{~V}$. 这类电池的主要限制因素在于如何合理选择各 个电池结构以获得最佳的电流分布.

\section{5 总结与展望}

有机/无机杂化太阳能电池在过去的几年中取得了 快速的发展, 本文主要概述了基于硅这种传统无机半导 体材料和有机物的新型杂化结构. 因为各种性能优异的 有机物纷纷出现，以及不断改进成熟的制备工艺和众多 科研工作者的努力，这种杂化太阳能电池已经初步实现 了低成本高效率. 总体而言, 对这类电池的性能提高主 要集中在这几个方面：(1)有机物的选择和改性，合适能 带的有机物决定了理论的最高效率，而提高其稳定性和 导电性等性质又是实现最佳性能的必要保障; (2)硅表面 的处理，包括采用陷光结构、表面钝化处理等，获得更 高的电流和低的表面复合速率; (3)电极的优化，降低接 触处的电阻和载流子损失. 通过溶液旋涂低温退火方法 形成的平面硅基和微纳硅基杂化太阳能电池效率都超 过了 $13 \%$. 硅纳米线等结构高效的吸光性能可以大大减 少使用的硅材料, 使得杂化太阳能电池的应用前景更为 广阔.

除了取得的进展之外, 杂化太阳能电池也需要解决 更多的问题. 相比无机太阳能电池, 杂化太阳能电池的 稳定性目前研究不多, 需要寻找更为稳定的有机材料和 利用更先进的封装技术. 目前实验室取得的效率大部分 是基于小面积器件的 $\left(\sim 1 \mathrm{~cm}^{2}\right)$, 相比目前的工业电池

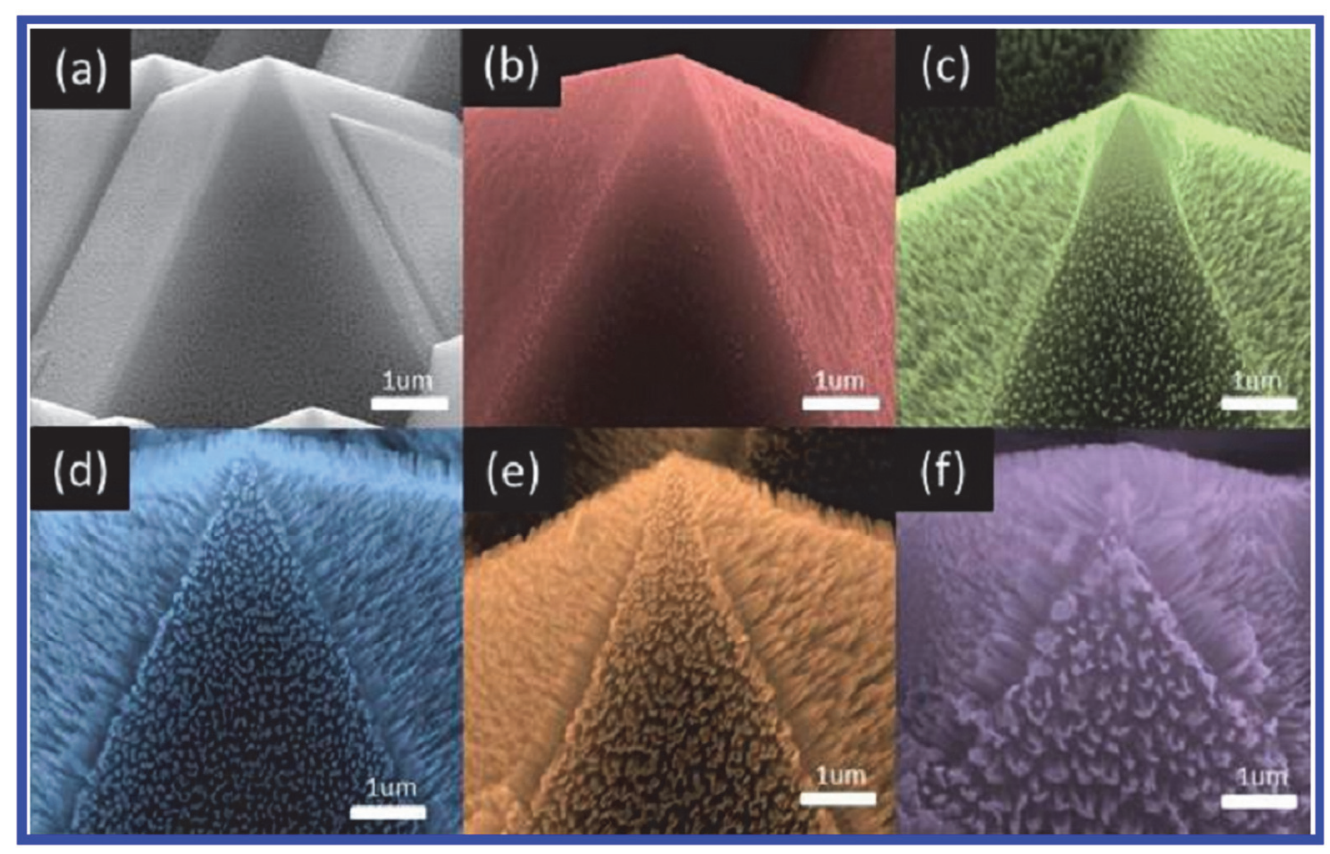

图 12 硅金字塔上制备硅纳米线的 SEM 示意图 ${ }^{[27]}$

Figure 12 SEM images of SiNWs on pyramids ${ }^{[27]}$ 
$\left(100 \mathrm{~cm}^{2}\right)$ 还需要很大的提高, 如何在扩大器件面积的同 时保持高效率是一个极大的挑战. 对于形貌控制, 界面 复合等问题还需要进一步研究以获得更高的效率, 相信 新技术的出现会使有机/无机杂化太阳能电池获得更好 的发展前景.

\section{作者简介}



刘瑞远, 1989 年出生, 博士生. 2011 年、2014 年在苏州大 学分别获得工学学士学位、硕士学位, 2014 年起在苏州大学功 能纳米与软物质研究院从事博士研究工作. 目前研究主要包 括硅纳米结构的制备与性能表征, 硅和有机物的杂化太阳能 电池等方向.

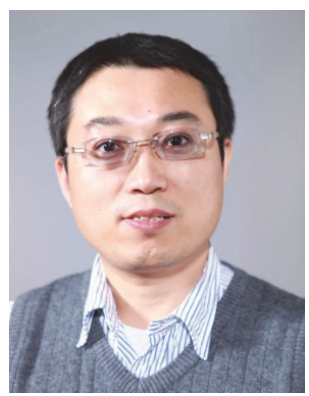

孙宝全, 1973 年出生, 教授. 1997 年、2002 年分别在青岛 科技大学、清华大学获得学士和博士学位, 先后在剑桥大学卡 文迪许实验室 $(2002 \sim 2007)$ 和洛斯阿拉莫斯国家实验室 (2007 2008)从事研究工作, 2008 年加盟苏州大学功能纳米与 软物质研究院(FUNSOM). 目前主要从事硅基光电材料和光伏 器件物理等方面的研究工作, 已经发表文章 80 余篇, 被他人 引用 4000 余次, H-因子 27.

\section{References}

[1] Green, M. A.; Emery, K.; King, D. L.; Igari, S.; Warta, W. Prog. Photovolt: Res. Appl. 2001, 9, 287.

[2] Tang, C. W. Appl. Phys. Lett. 1986, 48, 183.

[3] (a) You, J.; Dou, L.; Yoshimura, K.; Kato, T.; Ohya, K.; Moriarty, T.; Emery, K.; Chen, C.-C.; Gao, J.; Li, G.; Yang, Y. Nat. Commun. 2013, 4, 1446. (b) Liu, Z.; Xu, F.; Yan, D. Acta Chim. Sinica 2014, 72, 171. (刘震, 徐丰, 严大东, 化学学报, 2014, 72, 171.) (c) Fu, Y.; Wang, F.; Zhang, Y.; Fang, X.; Lai, W.; Huang, W. Acta Chim. Sinica 2014, 72, 158. (付钰, 王芳, 张燕, 方旭, 赖文勇, 黄维, 化 学学报, 2014, 72, 158.) (d) He, P.; Li, Z.; Hou, Q.; Wang, Y. Chin. J. Org. Chem. 2013, 33, 288. (和平, 李在房, 侯秋飞, 主艳玲, 有 机化学, 2013, 33, 288.)

[4] (a) Li, G.; Zhu, R.; Yang, Y. Nat. Photon. 2012, 6, 153. (b) Ye, H.; Li, W.; Li, W. Chin. J. Org. Chem. 2012, 32, 266. (叶怀英, 李文, 李维实, 有机化学, 2012, 32, 266.) (c) Fang, J.; Yu, X.; Yang, X.; Li, W.; An, D. Chin. J. Org. Chem. 2012, 32, 1261. (方敬坤, 俞宪,
杨金金, 李文风, 安德烈, 有机化学, 2012, 32, 1261.) (d) Liu, X.; Chen, C.; He, R.; Shen, W.; Li, M. Acta Chim. Sinica 2012, 70, 2365. (刘小锐, 陈春香, 何荣幸, 申伟, 李明, 化学学报, 2012, 70, 2365) (e) Cao, Z.; He, Z.; Deng, L.;Tan, S. Chin. J. Org. Chem. 2014, 34, 340. (曹镇财, 何舟, 邓利军, 谭松庭, 有机化学, 2014, 34, 340.)

[5] Fthenakis, V. M.; Kim, H. C. Solar Energy 2011, 85, 1609.

[6] Sailor, M. J.; Ginsburg, E. J.; Gorman, C. B.; Kumar, A.; Grubbs, R. H.; Lewis, N. S. Science 1990, 249, 1146.

[7] Huynh, W. U.; Dittmer, J. J.; Alivisatos, A. P. Science 2002, 295, 2425.

[8] He, W. W.; Wu, K. J.; Wang, K.; Shi, T. F.; Wu, L.; Li, S. X.; Teng, D. Y.; Ye, C. H. Sci. Rep. 2014, 4, 3715.

[9] Tian, B.; Zheng, X.; Kempa, T. J.; Fang, Y.; Yu, N.; Yu, G.; Huang, J.; Lieber, C. M. Nature 2007, 449, 885.

[10] Tsakalakos, L.; Balch, J.; Fronheiser, J.; Korevaar, B. A.; Sulima, O.; Rand, J. Appl. Phys. Lett. 2007, 91, 233117.

[11] Garnett, E.; Yang, P. Nano Lett. 2010, 10, 1082.

[12] Peng, K. Q.; Lee, S. T. Adv. Mater. 2011, 23, 198.

[13] Hu, L.; Chen, G. Nano Lett. 2007, 7, 3249.

[14] Peng, K.-Q.; Wang, X.; Li, L.; Wu, X.-L.; Lee, S.-T. J. Am. Chem. Soc. 2010, $132,6872$.

[15] Han, S. E.; Chen, G. Nano Lett. 2010, 10, 1012.

[16] Sai, H.; Kanamori, Y.; Arafune, K.; Ohshita, Y.; Yamaguchi, M. Prog. Photovolt: Res. Appl. 2007, 15, 415.

[17] Mavrokefalos, A.; Han, S. E.; Yerci, S.; Branham, M. S.; Chen, G. Nano Lett. 2012, 12, 2792.

[18] Cheng, H.-H.; Chang, Y.-Y.; Chu, J.-Y.; Lin, D.-Z.; Chen, Y.-P.; Li, J.-H. Appl. Phys. Lett. 2012, 101, 141113.

[19] Mavrokefalos, A.; Han, S. E.; Yerci, S.; Branham, M. S.; Chen, G. Nano Lett. 2012, 12, 2792.

[20] Riad, S. Thin Solid Films 2000, 370, 253.

[21] Williams, E. L.; Jabbour, G. E.; Wang, Q.; Shaheen, S. E.; Ginley, D. S.; Schiff, E. A. Appl. Phys. Lett. 2005, 87, 223504.

[22] El-Nahass, M. M.; Abd-El-Rahman, K. F.; Farag, A. A. M.; Darwish, A. A. A. Org. Electron. 2005, 6, 129.

[23] El-Nahass, M. M.; Zeyada, H. M.; Aziz, M. S.; Makhlouf, M. M. Thin Solid Films 2005, 492, 290.

[24] Avasthi, S.; Lee, S.; Loo, Y. L.; Sturm, J. C. Adv. Mater. 2011, 23, 5762.

[25] Jeong, S.; Garnett, E. C.; Wang, S.; Yu, Z.; Fan, S.; Brongersma, M. L.; McGehee, M. D.; Cui, Y. Nano Lett. 2012, 12, 2971.

[26] Liu, Q.; Ono, M.; Tang, Z.; Ishikawa, R.; Ueno, K.; Shirai, H. Appl. Phys. Lett. 2012, 100, 183901.

[27] Wei, W. R.; Tsai, M. L.; Ho, S. T.; Tai, S. H.; Ho, C. R.; Tsai, S. H.; Liu, C. W.; Chung, R. J.; He, J. H. Nano Lett. 2013, 13, 3658.

[28] Zhang, Y.; Zu, F.; Lee, S.-T.; Liao, L.; Zhao, N.; Sun, B. Adv. Energy Mater. 2015, 8, 297.

[29] Liu, R.; Lee, S. T.; Sun, B. Adv. Mater. 2014, 26, 6007.

[30] Wang, W.; Schiff, E. A. Appl. Phys. Lett. 2007, 91, 133504.

[31] Seo, J. H.; Kim, D. H.; Kwon, S. H.; Park, Y. C.; Jung, H. H.; Lee, H. W.; Kwon, J. D.; Park, S. G.; Nam, K. S.; Jeong, Y.; Ryu, S. Y.; Kang, J. W.; Kim, C. S. Phys. Chem. Chem. Phys. 2013, 15, 1788.

[32] (a) Liu, Q.; Khatri, I.; Ishikawa, R.; Ueno, K.; Shirai, H. Appl. Phys. Lett. 2013, 102, 183503. (b) Zhu, Y.; Song, T.; Zhang, F.; Lee, S. T.; Sun, B. Appl. Phys. Lett. 2013, 102, 113504.

[33] Pietsch, M.; Bashouti, M. Y.; Christiansen, S. J. Phys. Chem. C 2013, 117, 9049.

[34] Fang, X.; Song, T.; Liu, R.; Sun, B. J. Phys. Chem. C 2014, 118, 20238.

[35] Thomas, J. P.; Leung, K. T. Adv. Funct. Mater. 2014, 24, 4978.

[36] Erickson, A. S.; Zohar, A.; Cahen, D. Adv. Energy Mater. 2014, 4, DOI: $10.1002 /$ aenm.201301724.

[37] Pietsch, M.; Jäckle, S.; Christiansen, S. Appl. Phys. A 2014, 115, 1109.

[38] (a) Zhang, Y.; Liu, R.; Lee, S.-T.; Sun, B. Appl. Phys. Lett. 2014, 104, 083514. (b) Zhang, Y.; Cui, W.; Zhu, Y.; Zu, F.; Liao, L.; Lee, S.-T.; Sun, B. Energy Environ. Sci. 2015, 10.1039/C4EE02282C.

[39] Oh, J.; Yuan, H.-C.; Branz, H. M. Nat. Nanotechnol. 2012, 7, 743.

[40] Schmidt, V.; Wittemann, J. V.; Gösele, U. Chem. Rev. 2010, 110, 361.

[41] Huang, Z.; Geyer, N.; Werner, P.; de Boor, J.; Gösele, U. Adv. Mater. 2011, 23, 285.

[42] (a) Peng, K.-Q.; Lee, S.-T. Adv. Mater. 2011, 23, 198. (b) Liu, R.; Zhang, F.; Con, C.; Cui, B.; Sun, B. Nanoscale Res. Lett. 2013, 8 , 155. (c) Bai, F.; Li, M.; Huang, R.; Li, Y.; Trevor, M.; Musselman, 
K. P. RSC Adv. 2014. 4, 1794.

[43] Kayes, B. M.; Atwater, H. A.; Lewis, N. S. J. Appl. Phys. 2005, 97, 114302.

[44] Kelzenberg, M. D.; Turner-Evans, D. B.; Kayes, B. M.; Filler, M. A.; Putnam, M. C.; Lewis, N. S.; Atwater, H. A. Nano Lett. 2008, 8, 710.

[45] Shiu, S.-C.; Chao, J.-J.; Hung, S.-C.; Yeh, C.-L.; Lin, C.-F. Chem. Mater. 2010, 22, 3108.

[46] Lu, W.; Wang, C.; Yue, W.; Chen, L. Nanoscale 2011, 3, 3631.

[47] He, L.; Jiang, C.; Lai, D. IEEE Electr. Device Lett. 2011, 32, 1406.

[48] Shen, X.; Sun, B.; Liu, D.; Lee, S. T. J. Am. Chem. Soc. 2011, 133, 19408.

[49] He, L.; Jiang, C.; Rusli; Lai, D.; Wang, H. Appl. Phys. Lett. 2011, 99, 021104.

[50] He, L.; Jiang, C.; Wang, H.; Lai, D.; Rusli ACS Appl. Mater. Interfaces 2012, 4, 1704.

[51] Zhang, F.; Liu, D.; Zhang, Y.; Wei, H.; Song, T.; Sun, B. ACS Appl. Mater. Interfaces 2013, 5, 4678.

[52] Pudasaini, P. R.; Ruiz-Zepeda, F.; Sharma, M.; Elam, D.; Ponce, A.; Ayon, A. A. ACS Appl. Mater. Interfaces 2013, 5, 9620.

[53] Yu, P.; Tsai, C.-Y.; Chang, J.-K.; Lai, C.-C.; Chen, P.-H.; Lai, Y.-C.; Tsai, P.-T.; Li, M.-C.; Pan, H.-T.; Huang, Y.-Y.; Wu, C.-I.; Chueh, Y.-L.; Chen, S.-W.; Du, C.-H.; Horng, S.-F.; Meng, H.-F. ACS Nano 2013, 7, 10780.

[54] Zhang, J.; Song, T.; Shen, X.; Yu, X.; Lee, S.-T.; Sun, B. ACS Nano 2014, $8,11369$.

[55] Thiyagu, S.; Hsueh, C. C.; Liu, C. T.; Syu, H. J.; Lin, T. C.; Lin, C. F. Nanoscale 2014, 6, 3361 .

[56] Kalita, G.; Adhikari, S.; Aryal, H. R.; Afre, R.; Soga, T.; Sharon, M.; Koichi, W.; Umeno, M. J. Phys. D: Appl. Phys. 2009, 42, 115104.

[57] Kuo, C. Y.; Gau, C. Appl. Phys. Lett. 2009, 95, 053302.

[58] Huang, J.-S.; Hsiao, C.-Y.; Syu, S.-J.; Chao, J.-J.; Lin, C.-F. Sol. Energy Mater. Sol. Cells 2009, 93, 621.

[59] Eisenhawer, B.; Sensfuss, S.; Sivakov, V.; Pietsch, M.; Andrä, G.; Falk, F. Nanotechnology 2011, 22, 315401.

[60] Zhang, F.; Sun, B.; Song, T.; Zhu, X.; Lee, S. Chem. Mater. 2011, 23, 2084.

[61] Zhang, F.; Han, X.; Lee, S.-t.; Sun, B. J. Mater. Chem. 2012, 22, 5362 .

[62] Wu, Y.; Zhang, X.; Jie, J.; Xie, C.; Zhang, X.; Sun, B.; Wang, Y.;
Gao, P. J. Phys. Chem. C 2013, 117, 11968.

[63] Chen, T.-G.; Huang, B.-Y.; Chen, E.-C.; Yu, P.; Meng, H.-F. Appl. Phys. Lett. 2012, 101, 033301.

[64] Chen, J.-Y.; Yu, M.-H.; Chang, S.-F.; Sun, K. W. Appl. Phys. Lett. 2013, 103, 133901.

[65] Schmidt, J.; Titova, V.; Zielke, D. Appl. Phys. Lett. 2013, 103 183901.

[66] He, L.; Lai, D.; Wang, H.; Jiang, C.; Rusli Small 2012, 8, 1664

[67] Jeong, H.; Song, H.; Pak, Y.; Kwon, I. K.; Jo, K.; Lee, H.; Jung, G. Y. Adv. Mater. 2014, 26, 3445.

[68] Liu, C.-Y.; Holman, Z. C.; Kortshagen, U. R. Nano Lett. 2008, 9 , 449.

[69] Liu, C.-Y.; Holman, Z. C.; Kortshagen, U. R. Adv. Funct. Mater. 2010, 20, 2157.

[70] Ding, Y.; Gresback, R.; Liu, Q.; Zhou, S.; Pi, X.; Nozaki, T. Nano Energy 2014, 9, 25.

[71] (a) Chi, D.; Qi, B.; Wang, J.; Qu, S.; Wang, Z. Appl. Phys. Lett. 2014, 104, 193903. (b) Guo, W.; Liu, F.; Zhu, M.; Zhou, Y.; Liu, J. Phys. Status Solidi C 2011, 8, 2810. (c) Liu, K.; Qu, S.; Zhang, X.; Tan, F.; Wang, Z. Nanoscale Res. Lett. 2013, 8, 1. (d) Sheng, J.; Fan, K.; Wang, D.; Han, C.; Fang, J.; Gao, P.; Ye, J. ACS Appl. Mater. Interfaces 2014, 6, 16027. (e) Tang, Z.; Liu, Q.; Chen, Q.; Khatri, I.; Shirai, H. Phys. Status Solidi A 2014, 211, 1179. (f) Zhao, H.; Xie, D.; Feng, T.; Zhao, Y.; Xu, J.; Li, X.; Zhu, H.; Ren, T. Appl. Phys. Express 2014, 7, 031603. (g) Zhao, Y.; Xie, D.; Xu, J.; Feng, T.; Zhang, X.; Ren, T.; Zhu, M.; Zhu, H. PIERS Proceedings 2014.

[72] (a) Kim, T.; Jeon, J. H.; Han, S.; Lee, D.-K.; Kim, H.; Lee, W.; Kim, K. Appl. Phys. Lett. 2011, 98, 183503. (b) Kim, T.; Choi, J. Y.; Jeon, J. H.; Kim, Y.-S.; Kim, B.-S.; Lee, D.-K.; Kim, H.; Han, S.; Kim, K. Mater. Res. Bull. 2012, 47, 3040.(c) Seo, J. H.; Kim, D.-H.; Kwon, S.-H.; Song, M.; Choi, M.-S.; Ryu, S. Y.; Lee, H. W.; Park, Y. C.; Kwon, J.-D.; Nam, K.-S.; Jeong, Y.; Kang, J.-W.; Kim, C. S. Adv Mater. 2012, 24, 4523. (d) Qin, W.; Yu, W.; Zi, W.; Liu, X.; Yuan, T.; Yang, D.; Wang, S.; Tu, G.; Zhang, J.; Liu, F. S.; Li, C. J. Mater. Chem. A 2014, 2, 15303. (e) Albrecht, S.; Grootoonk, B.; Neubert, S.; Roland, S.; Wördenweber, J.; Meier, M.; Schlatmann, R.; Gordijn, A.; Neher, D. Sol. Energy Mater. Sol. Cells 2014, 127, 157.

(Cheng, F. 